\title{
La ACTUACIÓN DE LAS ASAMBlEAS PROVINCIALES EN HisPania BAJO EL GOBIERNO DE ADRIANO
}

The Proceedings of the Provincial Assemblies in Hispania during the Hadrian Period

MARÍA PILAR GONZÁLEZ-CONDE PUENTE ${ }^{1}$

(1) Departamento de Prehistoria, Arqueología, Historia Antigua, Filología Griega y Filología Latina. Universidad de Alicante.pilar.gonzalez@ua.es

\section{RESUMEN:}

El presente trabajo es una puesta al día de la información que se conserva para la época de Adriano sobre las actuaciones de las asambleas provinciales en Hispania a través de las fuentes literarias y epigráficas: las dedicaciones realizadas o permitidas por la asamblea, los individuos objeto de los homenajes, el papel de las ciudades como elemento de cohesión en los territorios provinciales, así como las consultas que la institución hizo frente al Príncipe y las tareas especiales que encargó a algunos miembros de las élites locales.

Palabras clave: Adriano, Hispania, concilium provinciae, provincia Hispania citerior, Baetica, Lusitania.

\section{Abstract:}

This paper is an update of the data preserved in the time of Hadrian on the proceedings of the provincial assemblies in Hispania, through literary and epigraphical sources: dedications made or permitted by the assembly, individual objects of tributes, the role of cities as elements of cohesion in the provincial territories, as well as the consultations that the institution posed to the emperor and, finally, special tasks that were entrusted to some members of the local elites.

Key words: Hadrian, Hispania, concilium provinciae, provincia Hispania citerior, Baetica, Lusitania. 
Las provincias hispanas se vieron afectadas ${ }^{1}$, durante los años de gobierno de Adriano, por una intensa actividad que influyó en la vida de las comunidades peninsulares e introdujo profundas reformas en la gestión imperial de estos territorios. El objetivo último era sin duda una mejor explotación de los recursos y para ello se procuraron transformaciones administrativas y legislativas destinadas a ordenar la relación de los hispanos con Roma y la dinámica económica de las tres provincias. En esta tarea, las diferentes administraciones (provincial, conventual y local) debieron tener un papel fundamental, bajo el control de una ferrera administración que no dejaba casi nada a la improvisación. En estas circunstancias, los órganos de representación política de los territorios hispanos parecen haber respondido con la misma eficacia.

Los concilia provinciarum, cuya actuación quedó muchas veces documentada en la epigrafía honorífica, tenían ya una actividad intensa al menos desde época flavia, tal y como ha quedado reflejado en las menciones al flaminado provincial y a la organización del culto imperial. La mayor parte de los testimonios se encuentran, como no puede ser de otra manera, en las capitales provinciales, sedes de la asamblea, en donde se conmemoraba la concesión de la más alta manifestación del culto a los emperadores muertos, el flaminado provincial, pero no faltaron dedicaciones de las ciudades a aquellos miembros de sus élites que consiguieron llegar al más alto cargo sacerdotal en su provincia. Entre los numerosos testimonios de la vida pública en Hispania ${ }^{2}$ durante el gobierno de Adriano, las asambleas de las tres provincias tuvieron una actividad diversa, pero que respondía a la misma dinámica que se venía produciendo desde los años de Vespasiano.

\section{EL CONCILIUM PROVINCIAE HISPANIAE CITE- RIORIS}

La asamblea con sede en Tarraco ostentaba la representación de una provincia extensa y diversa, que contaba con recursos estratégicos para Roma, como las minas de oro del NO peninsular, así como algunos de los más importantes puertos del comercio mediterráneo. La colonia había estado en el punto de mira del estado romano durante las guerras cántabras, debido a la presencia de Augusto en ella y, a la muerte del Príncipe, había pedido permiso a Tiberio para honrarle con un templo que hoy se considera ubicado en la parte más alta del trazado antiguo, junto al foro provincial. Algo más de un siglo después de estos acontecimientos, se produjo la llegada de Adriano quien, procedente de Britania y Galia, pasó en la ciudad el invierno de 122-123 d.C. (Halfmann 1986: 196; Syme 1988: 160-161; Birley 2000: 147; Id. 2004: 68). En el marco de esta visita, la oficina imperial debió aprovechar para realizar una gestión más cercana de los territorios hispanos, tal y como seguramente se hizo también en el resto de las provincias visitadas por el Príncipe (Boatwright 2000: 108-143). Algunas de las actuaciones imperiales en Hispania parecen estar vinculadas a esa visita, aunque las dificultades de datación precisa no permitan establecer una secuencia segura y las dudas sobre el verdadero itinerario peninsular no ayuden a extraer conclusiones.

Probablemente el episodio más conocido y discutido de esta visita es aquél al que se refiere la Historia Augusta (vita Hadr. 12,4) acerca de la celebración de una asamblea en Tarraco para impulsar el reclutamiento entre las comunidades hispanas. Según el biógrafo imperial, los Italici se habían burlado de la idea, mientras que los demás representantes de las ciudades se habían opuesto enérgicamente. Tal y como se ha aceptado en la actualidad, el término Italici hacía referencia a los descendientes de los colonos itálicos y no a los habitantes de Italica (Birley 2000: 148; Alföldy 2014: 16-17 con la bibliografía anterior), una interpretación que da sentido al episodio. Esta iniciativa para el reclutamiento pudo estar dirigida a los habitantes de la Citerior o bien a todos los hispanos (Alföldy 2014: 19), lo que habría supuesto que en la asamblea habría una representación interprovincial. En el primer caso, el Príncipe se iba a dirigir a la provincia más extensa, con tradición de estacionamiento de tropas y con capacidad para el reclutamiento de soldados, a través de su órgano de representación que era el concilium provinciae (Guiraud 1966:113-119). En el segundo caso, la circunstancia especial de la llegada del monarca a la Península habría supuesto la preparación de una reunión de todas las comunidades hispanas con estatuto privilegiado, que se habría desarrollado de forma independiente a cualquier celebración de la asamblea provincial de Tarraco aunque en la misma capital de la Citerior. Si las circunstancias fueron estas últimas, entonces es posible que Adriano presidiera dos asambleas en la ciudad: la reunión anual del concilium provinciae celebrada en otoñoinvierno para la designación del flamen que iba a comenzar su mandato a principios del siguiente año y algo más tarde la convocatoria dirigida al reclutamiento. Parece que, tanto el Príncipe como la provincia, no querrían 
renunciar a la presidencia imperial de la asamblea provincial que se debía celebrar cuando éste estuviera a punto de llegar a la Citerior.

De cualquier manera, resulta evidente que la convocatoria de los hispanos necesitaba un tiempo de preparación hasta que las ciudades enviaran a sus representantes, por lo que puede deducirse que esta reunión ya estaría en la mente de Adriano y de su oficina desde antes de llegar a Hispania. La razón era sin duda la necesidad de que las provincias aportaran hombres para las legiones y seguramente no fueron solo los hispanos quienes tuvieron esta exigencia. Algunas unidades peninsulares habían salido ya hacia Britania, en donde la visita del monarca habría servido a su vez para reorganizar los contingentes militares con vistas a la construcción del muro de Adriano (Birley 2000: 123-141 y n. 10 con la bibliografía). Tal y como ha explicado G. Alföldy, la persona encargada de organizar los nuevos contingentes militares que salieran de esta petición imperial pudo ser Ti. Claudius Quartinus ${ }^{3}$, legado jurídico de la Citerior ya desde el año 117 d.C. y confirmado todavía en el cargo el 9 de octubre de 119 por la respuesta que daba a la ciudad de Pompaelo sobre un caso de contumacia (CIL II 2959). A partir de la reconstrucción de una inscripción de Ostia (CIL XIV, $4473=$ CIL VI2/8.3,1567), se ha conocido su condición de comes de Adriano durante su viaje por Hispania y a continuación en oriente, al mando de dos legiones, la II Traiana y la III Cyrenaica, lo que ha permitido a G. Alföldy (2014: 19) llegar a la conclusión de que Quartinus conducía a Siria a los hombres reclutados en la Citerior (o en toda Hispania) durante la visita de Adriano, todavía como acompañante imperial (Birley 2000: 149 y 153). Así pues, la reunión en Tarraco habría sido el desencadenante de todo este proceso, que culminaría con la incorporación de algunos hispanos a las legiones y su salida (total o parcial) hacia Siria, bajo el mando de Quartinus y acompañando al Príncipe.

Es evidente que la visita del monarca a Tarraco provocaría desde varios meses antes una febril actividad para engalanar la ciudad, llevada a cabo sin duda desde la administración provincial y también local. Un ejemplo de la relación entre ambas se puede apreciar en la inscripción que la asamblea de decuriones dedicó a C. Calpurnius Flaccus y que él mismo pagó en uno de los más claros ejercicios de autorepresentación de un miembro de la élite (CIL II 4202; CIL II²/14, 1124 con la bibliografía). En el epígrafe (fig. 1) figuraba su condición de flamen $\mathrm{pHc}$, pero no era el desempeño de ese cargo el motivo del homenaje, una cuestión que habría sido competencia del concilio provincial, sino el encargo especial del cuidado del templo y de las murallas, en forma de una curatela de carácter extraordinario. La identidad del templo del que debía ocuparse temporalmente no está recogida, pero el hecho de que el encargo sea de la colonia dificulta la posibilidad de que se tratara del recinto de culto a Augusto (CIL II $2 / 14,1124$ con la discusión). El epígrafe, hoy perdido, estaría en algún lugar del foro colonial, dado que se hizo por orden de la asamblea de decuriones, aunque es previsible que el concilio provincial le hubiera dedicado antes un pedestal en el foro de la parte alta de la ciudad, al término de su año de sacerdocio. Desde el punto de vista de la representación institucional, el texto del pedestal de Flaccus quedó claramente dividido en dos partes: una primera en la que se hace el reconocimiento del sacerdocio provincial y una segunda en la que se deja constancia de que es la asamblea local el organismo que le ha encargado una tarea tan especial. Como el homenaje se hacía en el ámbito de actuación de la colonia, no fue

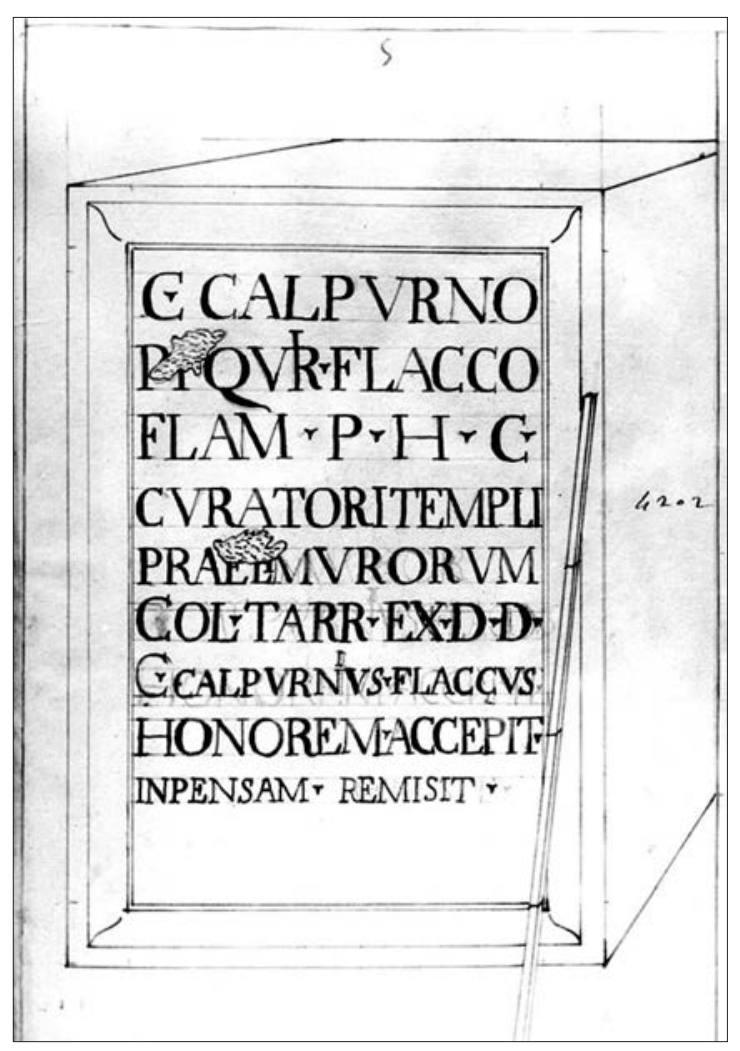

Fig. 1: Dibujo del pedestal de C. Calpurnius Flaccus (CIL II $2 / 14$, 1124). Según Alföldy, por cortesía de la BBAW. 
necesario indicar la origo del flamen provincial, como sí se hacía generalmente en las dedicaciones por el final de este sacerdocio (Fishwick 2002: 3.2: 12; CIL XII 6038; Williamson 1987: 185), aunque su tribu Quirina parece indicar que su patria de origen no fue Tarraco, sino alguna otra ciudad de la Citerior. En cualquier caso, este homenaje de la colonia sirve de vínculo con este flamen que presidió la asamblea provincial en Tarraco en una fecha no determinada, aunque bien pudo coincidir con los preparativos de la visita imperial (Alföldy 1973: n. ${ }^{\circ}$ 13; Plin. Ep. 5, 2).

La mayor parte de los documentos sobre el funcionamiento de la asamblea de Tarraco se refieren, como en otras provincias y en otros momentos, a las dedicaciones que el propio concilio ofreció a los flamines del culto provincial al finalizar su cargo. La topografía de los hallazgos de estos pedestales ha permitido localizar la zona que la ciudad de Tarraco dedicó a la administración provincial y la arqueología ha proporcionado la información sobre el foro provincial y su área de culto, ubicadas en la parte alta de la antigua colonia, separadas del resto del trazado urbano por el circo $^{4}$.

Entre la numerosa epigrafía hallada en el recinto, resultado de los homenajes que el concilium provinciae dedicó a los sacerdotes provinciales (Lozano 2013: passim), hay varios que se pueden datar en los años del gobierno de Adriano o en fechas próximas. Uno de ellos es el pedestal de L. Aemilius Paulus, originario de la ciudad

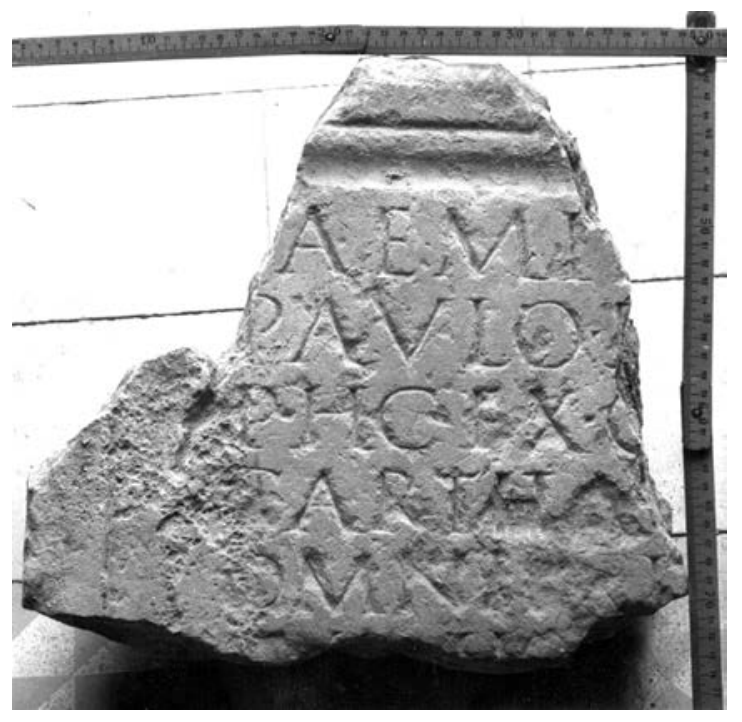

Fig. 2: Fragmento conservado del pedestal de L. Aemilius Paulus, de Attacum $\left(C I L I^{2} / 14,1111\right)$. Según Alföldy, por cortesía de la BBAW. de Attacum $^{5}$, de la que expresamente se dice que pertenecía al conventus Carthaginiensis y que ha servido para bajar hacia el S la localización de la ciudad (fig. 2). Originariamente ubicada en Ateca (Zaragoza), la mención del conventus hace imposible esta identificación, que hoy se lleva a algún lugar de la provincia de Cuenca. En su patria, L. Aemilius Paulus desempeñó las magistraturas de una carrera local, lo que en el homenaje se expresó con la fórmula omnibus in re publica sua honoribus functus, que resumía sus cargos y ha permitido establecer una fecha post quem, ya que el cambio desde la enumeración de los cargos individualizados hacia una forma resumida se consigna desde época de Adriano (Alföldy 1973: n. ${ }^{\circ}$; Ortiz de Urbina 1999: 128). Tras su cursus municipal, Aemilius Paulus inició una carrera ecuestre porque su fortuna e influencia le permitió acceder a este ordo (PME A 84; Curchin 1990: n. ${ }^{\circ}$ 416), en el que desempeñó dos cargos militares que le llevarían fuera de su patria de origen y de la península Ibérica: un tribunado militar angusticlavio en la legio III Cyrenaica y la prefectura de una cohorte indeterminada (CIL II $2 / 14,1111$ con la restitución). Aunque no parece posible fijar la fecha exacta del desempeño del tribunado (PME VI: 146, ca. 110), lo cierto es que L. Aemilius Paulus tuvo que desplazarse necesariamente a oriente, porque la legión estuvo primero en Egipto y luego en Arabia, a partir de la creación de esta provincia, aunque al menos una parte de ella participó en la guerra pártica durante el gobierno de Trajano ${ }^{6}$. Tras su estancia en oriente, el ecuestre estaría destinado en algún lugar no conocido por la imposibilidad de determinar la cohorte que mandó, ni si ésta estuvo en la península Ibérica o en otro territorio provincial. En cualquier caso, tras estos cargos militares, Paulus volvió a su provincia de origen y fue elegido para deempeñar el flaminado de la provincia Hispania citerior (CIL II2/14, 1111: ca. 120; Etienne 1974: 131 y 137: quizá Trajano; adrianea con reservas). Su situación como ecuestre que ya había cumplido con dos milicias le permitió volver como un personaje destacado de la élite de su ciudad e incluso alcanzar la representación provincial. La ciudad de Attacum enviaba así un destacado representante a la capital provincial, en consonancia con el papel que empezaban a jugar algunos pequeños y medianos municipios en el culto imperial de la Citerior desde época de Adriano, tomando el relevo en ocasiones a las grandes ciudades al proporcionar a un miembro de sus élites para el cargo (Alföldy 1973: 20-25 y 59; Fishwick 2002, vol. 3.2: 8789). La importancia que esta circunstancia tenía para 
algunas ciudades queda patente en el propio pedestal de Aemilius Paulus, en el que se hizo constar no solo la ciudad de origen sino también el conventus del que procedía. $\mathrm{Al}$ terminar el año del flaminado, el concilio provincial le dedicó una estatua con una inscripción, como venía siendo costumbre desde época flavia. El homenaje recogía de forma significativa la expresión de las tres administraciones afectadas: el municipio de Attacum (del que procedía el personaje), el conventus al que estaba adscrito (en el que a su vez el culto imperial era el principal elemento de cohesión) y la provincia Hispania citerior (en cuya capital desempeñaba el sacerdocio) (Ortiz de Urbina 2006: 5964). Bajo la fórmula provincia Hispania citerior, el concilio provincial, dedicante del homenaje, hacía constar toda esta información, seguramente con un doble objetivo: contentar al flamen originario de Attacum y dar visibilidad a las comunidades privilegiadas de la provincia precisamente en el lugar que las representaba, el foro provincial de Tarraco. La suerte posterior de Paulus no se conoce, aunque la entrada en el flaminado provincial pudo significar su vuelta definitiva a Hispania y con ello el abandono de una potencial carrera ecuestre.

Uno de los flamines de la $\mathrm{pHc}$ presentes en Tarraco y que pueden adscribirse, con más o menos seguridad, al período de Adriano, es un individuo originario de Saetabis (Xàtiva, Valencia) cuyo nombre se ha conservado solo parcialmente en la tradición manuscrita de un epígrafe hoy perdido. Se trata de $Q$. Fab[--- $] M[---]^{7}$, un miembro de una de las familias conocidas de la élite del municipio, los Fabii, suficientemente representados en la epigrafía local (Corell 2006: 29). Como tal, desempeñó los cargos de una carrera municipal, lo que se expresó con la fórmula omnibus honoribus in re publica sua functo, una forma más habitual que la de su predecesor y que parece remitir igualmente a una fecha no anterior a Adriano (vid. supra). A continuación fue promocionado al orden ecuestre por iniciativa imperial, lo que le incluye entre los notables de las ciudades de la Citerior que obtuvieron este privilegio por el favor de Adriano (vid. infra). Siguiendo el orden de su carrera propuesto por G. Alföldy y mantenido en la inscripción, fue a continuación elegido como juez de las cinco decurias, un puesto que pudo requerir su presencia en Roma ${ }^{8}$. A pesar de lo fragmentario de la transmisión del epígrafe, es razonable pensar que este saetabitano ocupó después una prefectura de una llamada cohors prima [---], que no es posible identificar con seguridad. Finalmente, alcanzó el flaminado de la provincia Hispania citerior en una fecha que ha sido calculada entre

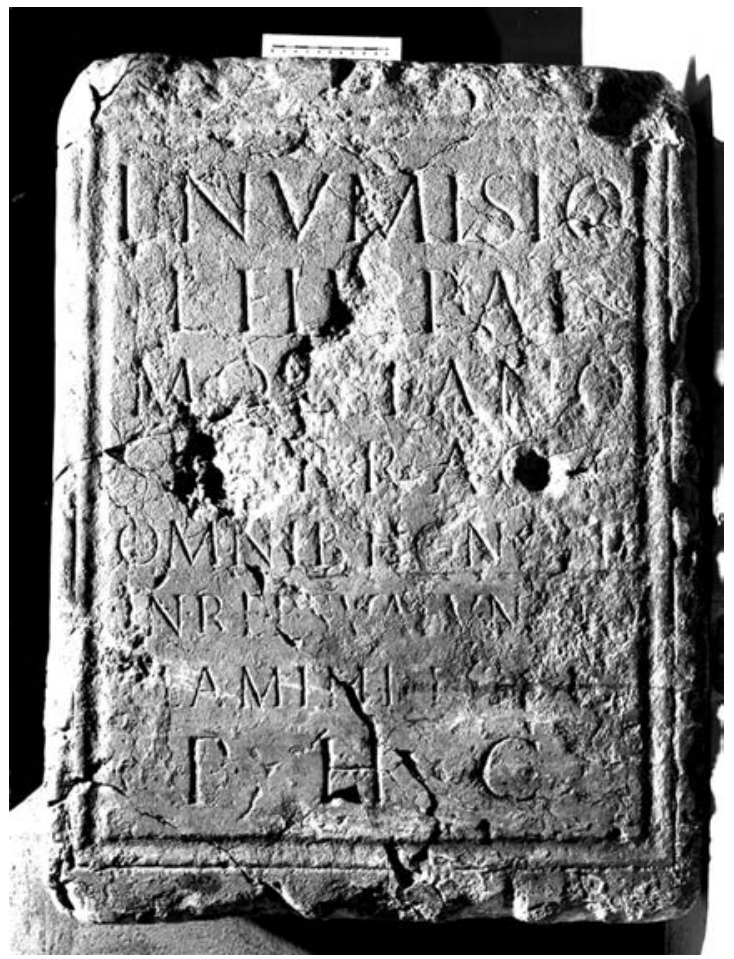

Fig. 3: Pedestal de L. Numisius Montanus (CIL II²/14, 1155). Según Alföldy, por cortesía de la BBAW.

los años 125 y 138 (Alföldy 1973: n..$^{\circ} 22$; CIL II $2 / 14$, 1133). Antes del 125 no sería posible por el plazo necesario entre la adlectio al orden ecuestre, realizada por Adriano, y el orden de sus cargos anteriores; después del 138 tampoco pudo ser porque en el texto figura el Príncipe todavía no divinizado. Al finalizar el desempeño del sacerdocio provincial, el concilio le dedicó un pedestal que, aunque perdido, ha dejado el rastro de una parte del texto que ha permitido reconstruir los términos del homenaje.

Entre las dedicaciones del concilium provinciae de Tarraco a sus flamines merece destacarse la presencia de los Numisii, originarios de la propia capital de la Citerior. Algunos de sus miembros desempeñaron cargos en la administración colonial y provincial, además de alcanzar el rango ecuestre, en el que desempeñaron alguna función aunque sin que haya quedado constancia de un cursus prolongado. El concilio de la provincia, que ofrecía un homenaje a sus flamines salientes, dedicó un pedestal a $L$. Numisius Montanus ${ }^{9}$ (fig. 3), de origen tarraconense y que había tenido una carrera local completa antes del flaminado, expresada con la fórmula omnibus honoribus in 
re publica sua functo (Alföldy 1973: n. ${ }^{\circ} 48$ ), como en el caso del sacerdote saetabitano. La asamblea hizo constar su origo, aunque era de la propia ciudad. El personaje es conocido también por otro pedestal que le dedicó su propia hermana, Numisia Victorina, que obtuvo permiso para colocarlo en el foro ${ }^{10}$, dejando testimonio esta vez de los cargos locales y su condición ecuestre. Siguiendo a G. Alföldy, Numisius Montanus habría recibido primero (o casi al mismo tiempo) la dedicación de su hermana y luego la del concilio provincial, de manera que el personaje pudo desempeñar, por este orden, los cargos locales, el ascenso al orden ecuestre y juez de decuria, para finalmente convertirse en sacerdote del culto imperial provincial (CIL II²/14, 1213; al contrario Etienne 1974: 138).

En cualquier caso, resulta evidente la diferencia de prioridades para los dedicantes de ambos pedestales. Numisia Victorina se ocupó de que la ciudad recordara la trayectoria de un hombre influyente como su hermano, que había sido edil, cuestor, duunviro y duunviro quinquenal, cargos todos ellos que aparecían pormenorizados. A continuación, recordaba que el propio Adriano, todavía vivo por entonces, le había promocionado al rango ecuestre y que también desempeñó la función de juez de la primera decuria de Roma. Esta información nos permite incluir a Numisius Montanus entre los miembros de las élites hispanas que obtuvieron su entrada en el orden ecuestre por iniciativa de Adriano. Este era el caso de $Q . F a b[---] M[---]$, de Saetabis (vid. supra); de C. Vibius Porcianus Quintius Italicianus, de Libisosa (Lezuza, Albacete); o de M. Fabius Paulinus, de Ilerda (Lleida) ${ }^{11}$. Al igual que Numisius Montanus, un individuo llamado M. Clodius Flaccus, de la élite de Labitolosa (La Puebla de Castro, Huesca), fue juez de las decurias de Roma, pero esta vez la iniciativa imperial consistió en proponerle para el cargo y no para el ascenso al rango ecuestre ${ }^{12}$.

Así pues, la dedicación a Numisius Montanus por parte de su hermana Victorina era un homenaje público, colocado en el locus celeberrimus, para dejar constancia permanente del papel que su hermano había jugado en la sociedad tarraconense. En cambio, la inscripción que el concilium provinciae dedicó a este personaje por su flaminado no destacó ningún otro cargo más que el que se quería señalar aquí, que suponía la presidencia de la asamblea provincial durante el año del desempeño del flaminado. Es imposible pensar que la dedicación de la hermana fuera posterior, porque con seguridad Numisius Montanus ocupó en primer lugar las funciones propias de un magistrado de la colonia. De esta manera, hay que admitir que la asamblea provincial de la Citerior destacó deliberadamente un único cargo, obviando el resto de su carrera pública al menos en lo referente a los cargos locales, aunque seguramente también en la mención al orden ecuestre y a la función de juez de decuria. Es posible que su origen local le hiciera tan conocido en la ciudad que no fuera necesario detallar su carrera pública en el pedestal que se iba a colocar en el foro provincial, como lo había hecho su hermana para el foro colonial.

La influencia social de Montanus afectaba también, como no podía ser de otra manera, a su mujer, Porcia Materna, natural de Osicerda (CIL II $4241=C I L \mathrm{II}^{2} / 14$, 1182). M. M. Alves (1978: 270-271) ha supuesto que su posición social le venía en realidad de su propia familia y era por tanto previa al matrimonio y habría ayudado a encumbrar a su marido. Sin embargo, hay que tener en cuenta que los sacerdocios recogidos en el epígrafe parecen estar en orden, de manera que Materna fue primero flaminica provincial (Alföldy 1973: n. ${ }^{\circ} 108$ ) y después local (Fishwick 2002, 3.2: 94 y 97-98; en contra Del Hoyo 2003: 106-109), respectivamente en tres ciudades con las que sin duda tenía algún grado de vinculación: Osicerda (su patria), Caesaraugusta (la capital del conventus del que procedía) y Tarraco (la patria de su marido y lugar de residencia), en donde fue flaminica perpetua (Etienne 1974: 248-249, flaminicas de varias ciudades). El orden de los cargos hace posible que el papel social de Materna se debiera a su marido, incluso que pudiera convertirse en flaminica provincial mientras este desempeñaba el mismo flaminado de la Citerior y que a continuación ese reconocimiento le reportara la concesión en las otras ciudades (Gregorio Navarro 2013-2014:148), en las que sin ninguna duda obtendría el reconocimiento social mediante una estatua y un pedestal.

El poder de los Numisii en Tarraco queda también patente por la carrera pública de L. Numisius Ovinianus, hermano de L. Numisius Montanus (CIL II $4232=$ CIL II2/14, 1156; PME N 21). El concilio provincial le dedicó un pedestal que ha permitido conocer su carrera pública. Como su hermano, ejerció las magistraturas en la colonia, que se expresaban bajo la fórmula omnibus honoribus in re publica sua functo (Alföldy 1973: n. ${ }^{\circ} 49$ ). A continuación alcanzó el rango ecuestre, aunque esta vez no hubo intención de dejar constancia del príncipe a quien se lo debía y, como tal, desempeñó un tribunado en la cohors I Macedonica ${ }^{13}$; no se puede asegurar si una parte o toda su carrera discurrió bajo el gobierno de Adriano o 
poco después de su muerte, dependiendo de la diferencia de edad con su hermano. Finalmente, siguiendo la línea de éste y de otros notables que volvieron a su provincia para culminar su promoción en un ámbito más cercano, ocupó el flaminado provincial y fue objeto del citado homenaje del concilio. Sin duda los intereses económicos de la familia estaban también en Italia (CIL XIV 397, sus posibles libertos).

Los Numisii tarraconenses (Caballos 1999: 475-476) no fueron los únicos con este nomen que alcanzaron el flaminado de la Citerior. Cn. Numisius Modestus, originario de Carthago Nova (Fig. 4) y con una carrera local previa (omnibus honoribus in republica sua functo), lo desempeñó también, seguramente en algún momento del gobierno de Antonino Pío (CIL II $4230=C I L \mathrm{II}^{2} / 14$, 1154; Alföldy 1973: n. $\left.{ }^{\circ} 47\right)$. Aunque por entonces ya había muerto Adriano, la labor de Modestus en Tarraco afectaba precisamente al recuerdo de este príncipe y por esa razón cabe citarlo aquí. Según reza la inscripción, hoy perdida pero de la que se conserva la lectura, Modestus fue el flamen de la provincia Hispania citerior encargado del dorado de las estatuas de Adriano (ad statuas aurandas), ya divinizado. El trabajo le había sido encomendado por el concilio de la provincia, tal y como reza el epígrafe, quien le dedicó finalmente el pedestal y la estatua, que no solo recordaba su cargo sacerdotal sino también la particular tarea de la que se había ocupado. La implicación de la provincia y su asamblea en el epígrafe era triple: fue responsable del encargo del trabajo al individuo homenajeado, era la institución cuya asamblea presidía este sacerdote y se ocupó de la dedicación del pedestal. En el foro provincial de Tarraco tuvo que haber también en su día una estatua con pedestal honrando a L. Numisius Laetus (Abascal y Ramallo 1997: n. 54 y 55 con la bibliografía), sin duda pariente y compatriota de Numisius Modestus, aunque no se haya conservado hasta la actualidad. Puede deducirse de su condición de flamen de la provincia Hispania citerior, una función que desempeñó dos veces y que se conoce por la dedicación de la asamblea de decuriones de su ciudad natal, Carthago Nova. La cronología aceptada para el personaje (Alföldy 1973: n. 46, ca. 100-150 d.C.) no nos permite adscribirlo con seguridad al período adrianeo, por lo que la referencia aquí se debe exclusivamente a su indudable parentesco con Numisius Modestus, quien sí pudo realizar al menos su carrera local (o parte de ella) bajo Adriano, a quien honró después de muerto desde el flaminado (Abascal 2012: 23-24 para padre e hijo).

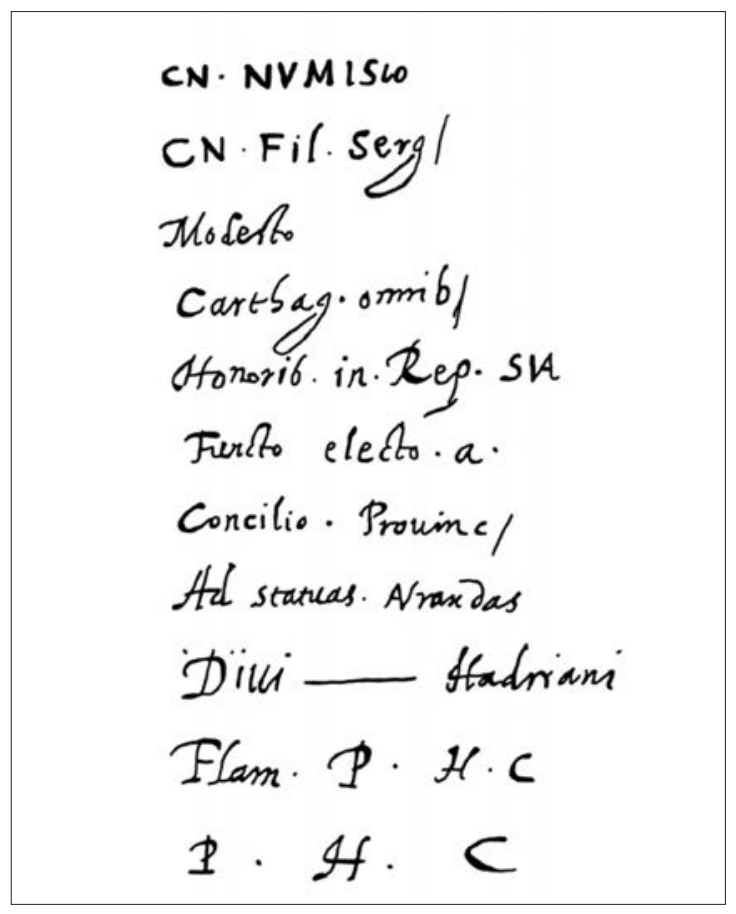

Fig. 4: Dibujo del pedestal de Cn. Numisius Modestus, de Carthago Nova (CIL II²/14, 1154). Según Alföldy, por cortesía de la BBAW.

Entre los miembros de las élites locales de la Citerior hubo algunos individuos que fueron promocionados al orden ecuestre por iniciativa de Adriano y en cuyos homenajes intervino de una u otra manera el concilium provincial. Ya se ha mencionado el caso de Numisius Montanus y de $Q$. Fab[---] $M[---]$, de Saetabis. Ambos comparten el haber alcanzado el orden ecuestre con el Príncipe y la condición de flamines de la $\mathrm{pHc}$, siendo este cargo el que les proporcionó una estatua con pedestal en el área del foro provincial de Tarraco. Un caso diferente fue la dedicación a M. Fabius Paulinus, un miembro de la élite de Ilerda del que se han conservado diversos homenajes en la epigrafía de Tarraco, aunque parece que ninguno fue hecho por la provincia (CIL II $\left.4269=C I L I^{2} / 14,1026\right)$. La asamblea provincial de la Citerior aceptó que se cumpliera un decreto de los decuriones de Ilerda por el que se ordenaba hacerle un homenaje en la capital provincial. El lugar sería el foro provincial porque eso es lo que explica que sea este concilio el que da el permiso. La causa por la que los Ilerdenses decidieron homenajear a Paulinus se expresa como civi optimo ob plurimas liberalitates in rem publicam suam. 
Constituye un ejemplo de cómo los concilios provinciales aceptaban iniciativas de las ciudades para colocar pedestales en el foro provincial, lo que sirve para hacerse una idea de la capacidad de acumulación de homenajes epigráficos a las élites locales en la capital de la Citerior. M. Fabius Paulinus recibió también en Tarraco una dedicación de quien pudo ser un liberto de su padre y otra de quien se definía como su discípulo y amigo (CIL II $2 / 14$, 1027; CIL II $2 / 14,1028)$. De todas ellas, sólo la primera se ha colocado con permiso de la asamblea provincial, lo que condicionaba su ubicación, pero las tres tienen en común que sin duda fueron encargadas y colocadas en Tarraco cuando Paulinus obtuvo el ascenso al rango ecuestre por concesión de Adriano, un dato que se observa en los tres epígrafes, sin que se mencionara una carrera pública previa (Alves Dias 1978: 264-267). Es muy probable que el personaje, sin duda con una gran capacidad de influencia en su ciudad de origen, no tuviera voluntad de desarrollar una carrera local en Ilerda ni provincial en Tarraco, porque de lo contrario, sus conciudadanos se habrían sentido orgullosos y lo hubieran hecho constar.

\section{Q. CALCIL1O \\ GAL.RVFINO}

Q.CAECILI

VALERINNIF.

SAGVNTINO.OB

LEGATIONEMQY

GRATV1TA.APVT

MAXIMVMiPRiNC

HADRIANVM-AVo

ROMAE.FVNCT.EST

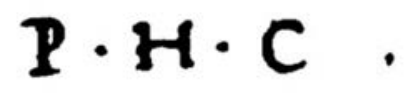

Fig. 5: Dibujo del pedestal de Q. Caecilius Rufinus, de Saguntum (CIL II $\left.{ }^{2} / 14,1192\right)$. Según Alföldy, por cortesía de la BBAW.
Entre los que se convirtieron en ecuestres con Adriano y obtuvieron algún reconocimiento por la asamblea de la provincia estaba $C$. Vibius Porcianus Quintius Italicianus, originario de Libisosa (CIL II $4254=$ CIL II $2 / 14,1173$ ). Durante el gobierno de Antonino Pío, obtuvo el flaminado provincial y como tal fue objeto de un homenaje por la asamblea de la provincia en donde se hacía constar su carrera local, mediante la fórmula omnibus honoribus in re publica sua functo, el sacerdocio y la promoción ecuestre a divo Hadriano, aunque se puso en primer lugar este último reconocimiento.

También bajo Antonino Pío desempeñó el flaminado provincial en Tarraco M'Valerius Capellianus (CIL II 4249 = CIL II $2 / 14,1169$ ), originario de Damania (Hinojosa de Jarque, Teruel) (Beltrán Lloris 2004: 71-74), aunque en este caso su sacerdocio se expresaba con la fórmula flamen Romae divorum et Augustorum (Alföldy 1973: n. ${ }^{\circ}$ 66). Capellianus había desempeñado las magistraturas locales en su ciudad de origen y luego había sido admitido mediante una adlectio en Caesaraugusta (Fasolini 2012: 52 y 268-269 para las tribus) por iniciativa de Adriano, que en la inscripción figuraba ya como divus (ex beneficio divi Hadriani). En su ciudad de adopción también desempeñó las magistraturas locales (utraque re publica). Se desconoce el motivo por el que Capellianus deseaba ser admitido como ciudadano de la capital del conventus al que pertenecía su ciudad de origen, pero lo que más llama la atención es la actuación imperial en un asunto tan cotidiano que no alcanzaría normalmente la atención de la oficina imperial. Cabe preguntarse si ésta fue una de las decisiones tomadas por el Príncipe durante su estancia en Tarraco, pero en ese caso hubo un intervalo de tiempo quizá demasiado grande, de al menos dos décadas, entre el favor de Adriano y el desempeño del flaminado provincial en Tarraco.

Todavía en vida de Adriano, la asamblea provincial dedicó un epígrafe a $Q$. Caecilius Rufinus (Fig. 5), un individuo originario de Saguntum y perteneciente a una influyente familia local de la que se conocen varias generaciones ${ }^{14}$. Rufinus había ido a Roma como miembro de una delegación enviada ante Adriano por el concilio provincial, una tarea que realizó de forma gratuita, siendo recompensado, seguramente en el momento de su vuelta, con un epígrafe de agradecimiento sufragado por la propia asamblea provincial. La familia de Rufinus proporciona un ejemplo perfecto de un grupo de la élite local que se promocionó progresivamente en diferentes generaciones, hasta que uno de sus miembros alcanzó el rango 
ecuestre en la generación siguiente a la de nuestro personaje. A la vista de esta trayectoria familiar, resulta atractivo pensar que Rufinus alcanzara responsabilidades locales y que después de éstas, estuviera en la capital provincial por un posible salto en su promoción personal, quizá un flaminado provincial del que no haya quedado constancia. Esto le habría obligado a vivir en Tarraco al menos temporalmente y le habría dado la vinculación precisa con el concilio provincial como para que fuera elegido para acudir ante el Príncipe. Se desconoce la fecha de la legación de Rufinus pero el epígrafe dice que el destino fue la ciudad de Roma, lo que limita considerablemente el período en que se pudo llevar a cabo, habida cuenta del poco tiempo que Adriano pasó en la capital del Imperio $^{15}$. En cuanto a los motivos, son también desconocidos, pero el encargo constituye un buen ejemplo de las funciones del concilio provincial que, como representante de las ciudades de su territorio, tenía capacidad para consultar directamente a la oficina imperial, en lugar de tratar un asunto con el gobernador provincial. En cualquier caso, esta legación de Rufinus no tiene por qué ser necesariamente un indicio de conflicto con el gobernador ya que muy bien podría tratarse de enviar al monarca la información sobre algún homenaje que la provincia fuera a dedicarle o cualquier otra cuestión. En este sentido, resultaría atractivo pensar que hubiera podido producirse con anterioridad a la visita imperial para tratar algún asunto propio de su preparación. En contra de esta idea se puede alegar que el viaje de Rufinus a Roma se habría hecho con demasiada antelación, ya que Adriano salió en 121 hacia Britania y todavía pasaría por Galia antes de alcanzar la península Ibérica (Birley 2000: 142-150). Sólo algún asunto que requiriera mucho tiempo podría haberse tratado de esta manera. En ese caso, Rufinus habría tenido que llegar a Roma el mismo año 121, antes de la salida de Adriano hacia las provincias occidentales. Desconocemos con qué antelación se comunicaba a las provincias la visita imperial, aunque la envergadura de algunas obras realizadas al amparo de este acontecimiento haría necesaria una importante previsión. Así ocurriría con la construcción del templo de Plotina en Nemausus o la restauración del templo de Augusto en Tarraco. Algunos de estos trabajos seguramente se iniciaron antes o durante la llegada del Príncipe (Birley 2000: 145 para Nemausus), pero es muy posible que algunas provincias quisieran ofrecer a la vista del monarca algunas de estas obras ya listas para su inauguración a su llegada a la capital. La asamblea de Tarraco debió tener encomendada una parte importante de las gestiones y de las tareas necesarias para recibir a Adriano y, en el marco de esta preparación, cabe pensar que Caecilius Rufinus fuera enviado a Roma para escenificar ante el Príncipe el interés de las comunidades de la Citerior por su visita. Esta demostración formal de fidelidad no impidió sin embargo que, una vez instalado Adriano en Tarraco, la presión para el reclutamiento entre las comunidades locales fuera recibida con hostilidad.

\section{EL CONCILIUM PROVINCIAE DE LA BÉTICA}

La provincia Bética no tiene una cantidad de información equiparable a la Citerior en lo que a las actuaciones del concilium provinciae se refiere ${ }^{16}$, pero hay una cuestión importante para el período estudiado. En un momento no determinado del gobierno de Adriano, la asamblea provincial de la provincia Bética, reunida en Cordu$\mathrm{ba}^{17}$ se puso en contacto con el Príncipe. Con toda seguridad lo hizo mediante una carta enviada al lugar del imperio en que se encontrara entonces, porque el motivo que movió a los provinciales en este caso, aún siendo grave, no parece que justificara un desplazamiento que requería tiempo y una cantidad considerable de dinero que saldría de las arcas públicas (Williams 1976: 68-69). Además, la respuesta vino en forma de rescripto imperial, tal y como quedó fijado en las fuentes jurídicas posteriores. La asamblea bética preguntaba acerca de la respuesta penal que se debía dar ante los delitos de robo de ganado (Pavón 2010: passim con la bibliografía). Las noticias sobre este rescripto adrianeo vienen de dos fuentes que no coinciden en su totalidad: el Digesto (47, 14, 1) y la Mosaicarum et Romanarum legum collatio $(11,7,13)$. El Digesto, al recoger el texto de Ulpiano sobre el rescripto de Adriano, orientaba la información en una doble dirección: definir en qué consistía el delito de abigeatus y explicar las penas que se podían aplicar según el caso. En lo primero, dejaba claro que cualquier castigo severo debía ser destinado a los que de verdad incurrieran en este delito, dejando penas más leves para quien en alguna ocasión sustrayera una cabeza de ganado o incluso para la posibilidad de un error en la adjudicación de la propiedad. No eran estos casos los que preocupaban a Ulpiano cuando se refería a este tema ni cuando evocaba el rescripto adrianeo. La segunda cuestión era más complicada y la respuesta ha sido objeto de discusión en lo que se refiere al alcance de las penas. 
Según el texto, Adriano ya había indicado que el castigo a los ladrones de ganado debía ser la pena capital allí donde el delito era más frecuente, mientras que debían quedar los trabajos forzados o en las minas para los demás supuestos. Esto significaba que el Príncipe contemplaba, en su forma de aplicar la justicia, diferentes castigos para un mismo delito en función de la frecuencia con que se daba en una región. Extraña sin embargo que, pudiendo contemplarse la pena máxima, hubiera a pesar de todo una consulta a la oficina imperial, aunque es posible que se tratara, en el caso de la Bética, de diferencias de criterio entre el gobernador provincial y la asamblea, o incluso entre los miembros de ésta última. También cabe la posibilidad de que la redacción posterior dejara poco claro si la pena capital era ya frecuente y aceptada desde el punto de vista jurídico antes del rescripto de Adriano (Santalucia 2009: 476-478). En cualquier caso, la discusión sobre este texto se ha centrado sobre todo en dos aspectos: si se consideraba la mina un castigo mayor o menor que la pena capital (a partir del texto de la Collatio), lo que queda confuso en el Digesto, aunque se acepta de forma mayoritaria y como no podía ser de otra manera, que la muerte era el más grave de los castigos; y el verdadero significado de la expresión ad gladium, que sería una condena a muerte más que un destino a los juegos gladiatorios (Pavón 2010: 286; Pietrini 1990: 470472), en donde el condenado habría podido tener más posibilidades de salvarse.

\section{EL CONCILIUM PROVINCIAE DE LUSITANIA}

El concilio de Lusitania ofreció en Augusta Emerita ${ }^{18}$ un homenaje a un senador llamado L. Roscius Aelianus (?) Maecius Celer Manlius (?) Postumus Mamilianus (?) Vergilius Staberianus (EE VIII, 302; PIR R 93), en el que se hacía alusión a su adlectio inter quaestores por iniciativa de Adriano (Cébeillac-Gervasoni 1972: 117119). La inscripción, realizada todavía en vida del Príncipe y reconstruida a partir del fragmento conservado, recogió la carrera del senador, quien, tras la cuestura, había desempeñado los cargos de sodalis augustalis, pretor peregrino y legado de la legio XIIII Gemina Martia Victrix (Alföldy 1969: 148 y n. 104). Ninguna mención a un cursus anterior a la adlectio, lo que ha hecho suponer que su carrera senatorial comenzó con el favor de Adriano para la cuestura, para este miembro de una familia que había dado ya varios cónsules al Imperio y los seguiría dando (Caballos 1990: 532). Se acepta de forma general que
Staberianus debió desempeñar el consulado en el año 136 ( $P I R^{2}$ R 93 con el debate), dejando a sus descendientes de las tres generaciones siguientes respectivamente la identificación con los cónsules de los años 155-159, 187 y 223. El primero de estos tres consulados ha sido identificado a partir de dos diplomas militares, de Moesia superior ( $A E$ $\left.1998, \mathrm{n}^{\circ} 1617\right)$ y Tracia $\left(A E 1998, \mathrm{n}^{\circ} 1627\right)$ respectivamente, como el desempeñado por L. Roscius Aelianus $\mathrm{Pa}$ culus, un hijo del Roscius emeritense (Settipani 2002: 24).

Se ha discutido si L. Roscius, el cónsul de 136 d.C., estuvo casado con Domitia Vetilla, una mujer de la élite de Vercellae (Vercelli, Italia) (Alföldy 1999: 328-329 con la bibliografía) que está presente en la epigrafía de Augusta Emerita junto a su marido. En la fachada principal del templo de Marte, en la colonia, figuraba su nombre como responsable de la construcción del edificio (CIL II 468), vinculado al cognomen de su marido: Marti sacrum Vetilla Paculi (León Alonso 1970: 194). Ambos fueron homenajeados también en la patria de Domitia por los sevires augustales de la ciudad. Este personaje parece ser el hijo del cuestor de Adriano y casi con toda seguridad el primero de la rama familiar que llevaba el cognomen Paculus (González Herrero 2007: 626), que luego se mantendría en las generaciones siguientes. Se trataba de L. Roscius Aelia[nus Paculus?], que habría alcanzado el consulado en 155-159 (Masier 2006: 110-111 con otra interpretación). Sobre la origo del Roscius emeritense, frente al debate anterior, ya Alföldy (1969, 149 n. 104) planteó que se trataba de un senador lusitano, para cuya familia W. Eck (1996: passim) ha visto un origen anterior en Sicilia. Desconocemos el lugar de residencia de Roscius hasta el momento del nombramiento como cuestor, aunque es muy probable que este senador, descendiente de individuos de rango consular, tuviera fijada su residencia en Roma, de donde saldría para desempeñar el cargo militar al mando de la legio XIIII Gemina. Los intentos de establecer una secuencia para el desempeño de estos cargos no ha dado resultado más allá de la ubicación de su carrera bajo el gobierno de Adriano.

\section{CONCLUSIONES}

Las actuaciones de los concilios de las provincias hispanas durante el gobierno de Adriano han proporcionado una información que resulta ser mucho más numerosa para la provincia Citerior, que por otra parte era la más extensa de las provincias hispanas. Esta desproporción se basa sobre todo en los hallazgos de los pedestales honoríficos de 
los flamines provinciales, así como de algunos miembros de la élite que llevaron a cabo tareas especiales encomendadas por la asamblea. En ambos casos, al terminar su trabajo, fueron objeto de un homenaje consistente en un pedestal con estatua, colocado en el foro provincial, en la parte alta del recinto urbano de la colonia tarraconense. El lenguaje parece ser distinto en función del organismo que encarga la inscripción, como se puede apreciar en el caso de L. Numisius Montanus.

La documentación epigráfica conservada es de dos tipos: las dedicaciones a los miembros de las élites locales que han recibido un homenaje en la capital por iniciativa de la asamblea provincial, en virtud de su cargo o de una actuación extraordinaria encargada por este organismo; y las consultas jurídicas que el concilio hacía directamente al emperador, sin la mediación del gobernador provincial, como en el caso del rescripto de Adriano en respuesta a una consulta de la asamblea bética sobre el robo de ganado. En el primer caso, la anualidad del flaminado provincial hace que hayan aumentado las posibilidades de encontrar los pedestales, que en Tarraco dan una secuencia más numerosa desde época flavia hasta el final de Adriano, con varios individuos que, con total o parcial seguridad, desempeñaron su sacerdocio durante los años de este monarca. En el segundo caso, la escasez de datos para este período se compensa con la importante aportación que dan a las funciones y a los límites de las competencias de los concilia provinciarum. Si la documentación epigráfica es prioritaria, no es menos importante la información de las fuentes literarias, como ocurre en el caso de la asamblea de Tarraco durante la visita del Príncipe o del rescripto sobre el robo de ganado recogido en el Digesto.

En el caso del concilio de Tarraco, las inscripciones de los flamines han permitido deducir que, para la época de Adriano, diversas ciudades de la provincia que no habrían tenido hasta entonces un protagonismo especial, pudieron situar a uno de sus próceres en la presidencia del concilio. Así ocurrió con ciudades como Attacum, Saetabis, Libisosa o Damania. En el caso de estas dos últimas, el flaminado provincial transcurrió bajo el gobierno de Antonino Pío, pero ambos personajes habían recibido algún tipo de promoción por el favor de Adriano. Este posicionamiento de algunas ciudades no impidió, sin embargo, que el flaminado provincial en la Citerior fuese también desempeñado por miembros de la élite de la capital tarraconense, como ocurrió con los Numisii. En cuanto a las otras provincias, si la información es escasa, también es muy significativa: en la Bética, por la noticia sobre la respuesta de carácter jurídico dada por el monarca al concilio de la provincia; en Lusitania, por la posibilidad de conocer un homenaje de la asamblea a un senador originario de la provincia.

La importancia y diversidad de las actuaciones de los concilia durante este período estaría sin duda en consonancia con la ingente tarea administrativa y legislativa llevada a cabo por Adriano en las provincias hispanas, como en el resto del Imperio, por parte de una oficina imperial casi en permanente movimiento. Sin duda los concilia de las tres provincias tendrían una actuación intensa y destacada antes y durante la visita y estancia del Príncipe entre los años 122-123. Ya se ha considerado que el encargo que la asamblea de la Citerior hizo a C. Calpurnius Flaccus, quien precisamente había presidido este organismo en calidad de flamen provincial, debió estar relacionado con esta presencia imperial. Se puede añadir también la posibilidad de $Q$. Caecilius Rufinus aceptase viajar a Roma en el año 121 d.C., como legado de la asamblea provincial, en el marco de los preparativos de este acontecimiento. En el caso de Rufinus además hay que tener en cuenta su origen saguntino, lo que demuestra que la asamblea provincial de la $\mathrm{Ci}$ terior no reservaba estos asuntos tan trascendentes exclusivamente para la élite de Tarraco, sino que los representantes de otras ciudades con la suficiente influencia y riqueza podían ser también objeto de estos encargos que tantos honores comportaban.

\section{NOTAS}

1. Este trabajo se ha realizado en el marco del proyecto de investigación HAR2015-65168-P de la Secretaría de Estado de Investigación, Desarrollo e Innovación del Gobierno de España.

2. Cuando se habla de la península Ibérica en época romana, debe utilizarse el término "Hispania" y no España (l'Espagne, Spain, Spanien) como es frecuente encontrar en la bibliografía científica. La razón es la misma por la que nunca decimos Alemania (Alemagne, Germany, Deutschland) para referirnos a Germania; ni Francia (France, Frankreich) para hablar de Gallia; ni Inglaterra o Reino Unido (Angleterre, England) en referencia a Britannia. España es el nombre de un estado actual que deriva del término latino Hispania, pero no corresponde a la misma realidad histórica ni a idéntico territorio, por lo que la identificación no es válida. Un caso diferente es el nombre de Italia, que en época romana tenía un sentido geográfico, relativo a la península Itálica, por lo que su uso en los estudios de Historia Antigua está perfectamente justificado.

3. Entre la amplia bibliografía sobre la carrera de Ti. Claudius Quartinus: PIR ${ }^{2}$ C 990 (con el resto de las inscripciones que le mencionan); D'Ors 1953: 353-355; Camacho-Evangelista 1966: 299-319; Alföldy 1969: 79-81; PME C 177 (con toda la bibliografía); Alföldy 1977, 111, 120 nota 54, 212 y 269; 
Espinosa 1983: 312-313; Thomasson 1984, col 39, n. ${ }^{\circ} 8$, col 226, n. ${ }^{\circ}$ 126; Abascal, 2010: 744-745; Id. 2011: 300; Ozcáriz 2013: 153 y nota 1164; Alföldy 2014, 19.

4. Alföldy 1973: desplegable; CIL II $2 / 14$, XCV-CIII con un resumen de la topografía de la ciudad y la bibliografía. Entre los numerosos trabajos sobre el foro provincial de Tarraco y su área de culto: Hauschild 1972-74: 30-44; Aquilué i Abadias 1982-83: 173-186; Dupré i Raventós 1986: passim; TED’A 1989: 182-191; Mar Medina 1993, passim; Rovira i Soriano 1993: 207-217; Ruiz de Arbulo 1993: 98-100; Id. 1998: 48-57; Id. 2007, passim; Macias et al. 2007: 13-15; Mar Medina et al. 2013: 26-32; Id. et al. 2015: 67-169; Macias y Rodà 2015: 123-124. También Panzram 2002, 23-127 (para la ciudad de Tarraco) y especialmente 50-56 (para el culto imperial de la provincia, su funcionamiento y sus espacios).

5. CIL II $4189=$ RIT $253=$ CIL II ${ }^{2} / 14,1111$ (con la tesis actual sobre la localización de la ciudad); Alföldy 1973: n. ${ }^{\circ} 2$. Sobre la localización de Attacum: Ptol. 2,6,58; Lostal Pros 1980: 191, identificándola con Ateca (Zaragoza) y con la bibliografía anterior; Alföldy 1987: 90-91, entre Segobriga y Valeria; Alföldy y Abascal 2009: 512 (al NE de Valeria). Sobre las élites tarraconenses venidas de otros lugares peninsulares, a propósito del caso de C. Valerius Avitus bajo Antonino Pío, vid. Ruiz de Arbulo 2014, 132-134 y passim.

6. Entre la bibliografía: Speidel 1977: 691-695; Bowersock 1994, 106 y 157; Le Bohec 2015, vol. III: 1043. La legión estuvo en Egipto y luego fue trasladada a Arabia, en donde está documentada el 107 d.C. En el 115, se nombra una vexillatio en Dura Europos. En 119 se la vuelve a mencionar en Egipto, aunque Speidel advierte de que quizá se pueda explicar porque el campamento haya conservado el nombre de la unidad que había estado acantonada allí hasta ser enviada a Arabia.

7. CIL II $4213=$ RIT $273=$ CIL II ${ }^{2} / 14,1133$ con la transmisión manuscrita; PME F 9; Alföldy 1973: n. ${ }^{\circ} 22$; Rodríguez Neila 1978: n. ${ }^{\circ}$ 6; Caballos Rufino 1999: 486 y T 41; Curchin 1990: 219, n. ${ }^{\circ} 839$; Abascal 2011: 238-239.

8. Para el orden de su carrera: Alföldy 1973: n. ${ }^{\circ} 22 ;$ RIT 271; CIL $\mathrm{II}^{2} / 14,1133$. Para otro ejemplo de individuo que fue juez de las decurias de Roma y flamen provincial en Tarraco: Rodríguez Neila 1978: n. ${ }^{\circ}$ 3; González-Conde Puente 2011: 146.

9. CIL II $4231=$ RIT $295=$ CIL II'/14, 1155; PME N 21; Alves Dias 1978: 268-271. Del mismo individuo: CIL II 4275 = RIT $349=$ CIL II'/14, 1213. Abascal 2012: 24-25 (suya y de su hermano).

10. CIL II $4275=$ RIT $349=C I L \mathrm{II}^{2} / 14,1213$ : con permiso del concilio provincial. En contra: Ruiz de Arbulo 1990: 135, que piensa en la colonia. Para Numisia Victorina, también CIL $\mathrm{II}^{2} / 14,2248$, dedicada a su marido Furius Montanus. Gorostidi i Pi 2010: 80; Mar Medina et al. 2015, 270-272.

11. No se incluye CIL II 5941, de Caravaca, considerada falsa, que menciona una supuesta promoción al orden ecuestre de $L$. Aemilius Rectus por Adriano, aunque no el personaje, que figura en otros epígrafes: CIL II 3423 y 3424 de Cartagena; $C I L$ II 5942 de Caravaca; Abascal y Ramallo 1997: 59 y 60. Como la falsa de Caravaca es la única que nombra a Adriano, el personaje no es relevante para este trabajo. Sobre la importancia de estas promociones: Alves Dias 1978: 264.

12. CIL II 3008 y Supp. $5837=A E 1995,892=H E p$ 6, 1996, 600; Sillières et al. 1995: 115-118.

13. Cheesmann 1968: 28-29 para las cohortes equitatae. Documentada con posterioridad en Cirenaica: Goodchild y Reynolds 1962: 39; AE 1969-70, 636 y 637 (de Cirenaica, nombrando la unidad); $A E$ 1989, 626 (diploma); Spaul 2000: 138 (para quien la cohors I Macedonica sería la primera cohorte de la legio IIII Macedonica); Holder 2003: 113.
14. CIL II $4201=$ CIL II $/ 14,1192$ con stemma: estaría colocada en el foro provincial, junto a $C I L \mathrm{II}^{2} / 14,1191$ (de un individuo de Iuliobriga, por sus servicios a la provincia); Corell 2002: 137 (para Rufinus), 59, 353 y 432 (para la familia y sus propiedades).

15. Siguiendo a Birley 2004: 68, estuvo en Roma en: 118-121, 125 (desde 8/9) hasta 127 (hasta 3-3-127); 127 (desde 1-8127) a 128 (1/2 mitad) y desde 134 (5-5-134) hasta su muerte (en Roma y Tívoli). Se desconoce si la legación fue antes o después de la visita de Adriano a Tarraco.

16. No se tratan aquí los casos de dos flamines provinciales sobre los que se ha defendido una cronología adrianea. No hay seguridad de que estos dos flamines provinciales lo fueran bajo Adriano, por lo que se dejan fuera de este estudio. El primero de ellos es C. Aemilius Niger Arvacus, de Sexi (CILA IV, 169). El segundo es M. Cassius Caecilianus, de Italica (CILA II.2, 343).

17. El epígrafe se colocaría en el foro provincial. Sobre el uso de estos espacios en general y en concreto para Corduba, entre la amplia bibliografía: Trillmich 1990: passim; Panzram 2003: 125-129.

18. Tendría que estar en el foro provincial. Un estado de la cuestión sobre este espacio, con el resto de la amplia bibliografía, puede verse en: Nogales y Álvarez 2003: 435-449; Jiménez Salvador 2006: 11-28. Sobre la epigrafía como indicador del uso de este espacio de culto provincial: Stylow 2006: 297-314.

\section{BIBLIOGRAFÍA}

ABASCAL, J. M. (2011): La administración itinerante en la Hispania citerior. El funcionario y su familia, Viajes y cambios de residencia en el mundo romano (J.M. Iglesias; A. Ruiz, eds.), 289-317.

ABASCAL, J. M. (2009-2012): Diccionario Biográfico Español, Madrid (vol. 13, 2010: Claudius Quartinus, 744-745; vol. 18, 2011: Q. Fabius M[---],238-239; vol. 38, 2012: Numisius Laetus, Numisius Modestus, Numisius Montanus, Numisius Ovinianus, 23-25).

ABASCAL, J. M.; RAMALLO, S. (1997): La ciudad de Carthago Nova: la documentación epigráfica, 2 vols, Murcia.

$A E=$ L'Année Épigraphique (varios vols.), Paris.

ALFÖLDY, G. (1969): Fasti Hispanienses. Senatorische Reichsbeamte und Offiziere in den spanischen Provinzen des römischen Reiches von Augustus bis Diokletian, Wiesbaden.

ALFÖLDY, G. (1973): Flamines Provinciae Hispaniae Citerioris, Anejos de AEspA 6, Madrid.

ALFÖLDY, G. (1977): Konsulat und Senatorenstand unter den Antoninen. Prosopographische Untersuchungen zur senatorischen Führungsschicht, Bonn.

ALFÖLDY, G. (1987): Römisches Städtewesen auf der neukastilischen Hochebene. Ein Testfall für die Romanisierung, Heidelberg.

ALFÖLDY, G. (1999): Städte, Eliten und Gesellschaft in der Gallia Cisalpina: Epigraphisch-historische Untersuchungen, Stuttgart. 
ALFÖLDY, G. (2014): Hadrians Besuch in Tarraco, Historia Augusta. Colloquium Nanceiense. Atti dei Convegni sulla Histora Augusta XII (C. Bertrand-Dagenbach; F. Chausson, eds.), Bari, 11-29.

ALFÖLDY, G.; ABASCAL, J. M. (2009): Aemilius Paulus, L., Diccionario Biográfico Español, vol. 1, Madrid, 512.

ALVES, M. M. (1978): M. Fabius Paulinus y L. Numisius Montanus. A contribution to the knowledge of the hispanic municipal elites under Hadrian, MM 19, 1978, 263-271.

AQUILUÉ, X. (1982-83): Aportacions al coneixement de la terrasa superior de Tàrraco en l'època alt-imperial, Butlleti Arqueològic 4-5,165-186.

BELTRÁN, F. (2004): Sobre la localización de Damania, Leonica, Osicerda y Orosis, Paleohispanica 4, 67-88.

BIRLEY, A. R. (2000): Hadrian. The Restless Emperor, London New York (1. a ed. 1997).

BIRLEY, A. R. (2004): Los viajes de Adriano, Adriano Augusto (J. M. Cortés, E. Muñiz, eds.), Sevilla, 57-69.

BOWERSOCK, G. W. (1994): Roman Arabia, Cambridge (Massachusets)-London (1. a ed. 1983).

CABALLOS, A. (1999): Los caballeros romanos originarios de las provincias de Hispania. Un avance, L'Ordre équestre. Histoire d'une aristocratie (IIe siècle av. J.-C. - IIIe siècle ap . J.-C.) (S. Demougin; H. Devijver; M.-T. Raepsaet-Charlier, eds.), Roma 463-512.

CAMACHO-EVANGELISTA, F. (1963): La epistula de Claudio Quartino y el proceso de contumacia en las provincias (provincia Tarraconense), Revue internationale des droits de l'antiquité ser. 3, vol 10, 299-319.

CÉBEILLAC-GERVASONI, M. (1972) : Les quaestores principis et candidati aux Ier et Ilème siècles de l'Empire, Milano.

CIL II = HÜBNER, E. (1869): Corpus Inscriptionum Latinarum, vol. II, Berlin.

CIL II²/14 = ALFÖLDY, G. (2011-2012): Corpus Inscriptionum Latinarum, vol. II (editio altera), Fasc. 14, Colonia Iulia Urbs Triumphalis Tarraco, Berlin.

CIL VI²/8.3= ALFÖLDY, G. (2000): Corpus Inscriptionum Latinarum, vol. VI, pars VIII, fasc. III. Titulos magistratuum populi Romani ordinum senatorii equestrisque thesauro schedarum imaginumque ampliato, Berlin.

CIL XII = HISRSCHFELD, O. (1888): Corpus Inscriptionum Latinarum, vol. XII, Inscriptiones Galliae Narbonensis Latinae, Berlin.

CIL XIV = DESSAU, H. (1887): Corpus Inscriptionum Latinarum, vol. XIV, Inscriptiones Latii veteris Latinae. Berlin.

CILA II.2 = GONZÁLEZ, J. (1991): Corpus de inscripciones latinas de Andalucía, vol. II: Sevilla. Tomo II. La Vega (Italica), Sevilla.

CILA IV = PASTOR, M. (2002): Corpus de inscripciones latinas de Andalucía, vol. IV: Granada, Sevilla.

CORELL, J. (2006): Inscripcions romanes del País Valencià, III (Saetabis i el seu territori), Valencia.

CURCHIN, L. A. (1990): The Local Magistrates of Roman Spain, Toronto-Buffalo-London.
DEL HOYO, J. (2003): El sacerdocio femenino, medio de integración de la mujer en las estructuras municipales de Gobierno, Epigrafía y sociedad en Hispania durante el Alto Imperio: estructuras y relaciones sociales. Actas de las mesa redonda organizada por la Casa de Velázquez, el Centro CIL II de la Universidad de Alcalá y L'Année épigraphique (A. U. Stylow; S. Armani; H. Martineau, eds.), Madrid Alcalá de Henares, 129-131.

D'ORS, A. (1953): Epigrafía jurídica de la España romana, Madrid. DUPRÉ, X. (1987): Forum provinciae Hispaniae citerioris, Los foros romanos en las provincias occidentales. Valencia 1986 (C. Aranegui, ed.), Madrid, 25-30.

ECK, W. (1996): Senatorische Familien der Kaiserzeit in der Provinz Sizilien, ZPE 113, 109-128.

EE VIII = (1899): Ephemeris epigraphica: Corporis inscriptionum latinarum supplementum, Berlin.

ESPINOSA, U. (1984): Iuridici de la Hispania citerior y patroni de Calagurris, Gerión 1, 305-325.

ÉTIENNE, R. (1974): Le culte impérial dans la Péninsule Ibérique d'Auguste à Dioclétien, Paris.

FASOLINI, D. (2012): Le tribù romane della Hispania Tarraconensis. L'ascrizione tribale dei cittadini romani nelle testimonianze epigrafiche, Milano.

FISHWICK, D. (2002): The Imperial Cult in the Latin West. Studies in the Ruler Cult of the Western Provinces of the Roman Empire, vol 3.2, Leiden - Boston - Köln.

FLANDES, E.; BERMÚdEZ, A.; PALAU, R.; PUJANTE, P. (1994): Noves aportacions al coneixement de les estructures del Concilium Provinciae Hispaniae Citerioris ("Tarraco"), La ciutat en el món romà = La ciudad en el mundo romano (X. Dupré Raventós, ed.), XIV Congrés Internacional d'Arqueologia Clàssica, Tarragona 1993, 60-61.

GONZÁLEZ HERRERO, M. (2007): Origen familiar y procedencia: el ejemplo de la rama A de la familia Roscia, Acta XII Congressus Internationalis Epigraphiae Graecae et Latinae, Barcelona 2002 (M. Mayer; I. Baratta; A. Guzmán, eds.), Barcelona, 621-627.

GONZÁLEZ-CONDE, M. P. (2011): Los Domitii de Consabura y una noticia de Frontino, Lucentum 30, 143-149.

GOODCHILD R. G.; REYNOLDS, J. M. (1962): Some Military Inscriptions from Cyrenaica, PBSR 30, 37-46.

GOROSTIDI, D. (2010): Ager Tarraconensis 3. Les inscripcions romanes, Tarragona.

GREGORIO, M. C. D. (2013-14): Flaminica sive sacerdotes de la provincia Hispania Citerior: el sacerdocio femenino del culto imperial, HA 37-38,137-163.

GUIRAUD, P. (1966): Les assemblées provinciales dans l'Empire Romain, Roma.

HALFMANN, H. (1986): Itinera Principum. Geschichte und Typologie der Kaiserreisen im römischen Reich. Wiesbaden.

HAUSCHILD, Th. (1972-74): römische Konstruktionen auf der oberen Stadtterrasse des antiken Tarraco, AEspA 45-47, 3-44.

HEp $=$ Hispania Epigraphica $($ varios vols.), Madrid. 
HOLDER, P. (2003): Auxiliary deployment in the reign of Hadrian, Documenting the Roman army: essays in honour of Margaret Roxan (J.J. Wilkes, ed.), London, 101-145.

JIMÉNEZ, J. L. (2006): Presentación. El conjunto provincial emeritense en el contexto del culto imperial en Hispania, El Foro Provincial de Augusta Emerita: un conjunto monumental de culto imperial (P. Mateos, ed.), Anejos de AEspA 42, 11-28.

LE BOHEC, Y. (2015): The encyclopedia of the roman army, West Sussex, 3 vols.

LEÓN, P. (1970): Los relieves del templo de Marte en Mérida, Habis 1, 181-197.

LOZANO, F. (2013): Los concilios ciudadanos y el culto imperial, La administración de las provincias en el imperio romano (J. M. Blázquez; P. Ozcáriz, eds.), Madrid,177-198.

MACIAS, J. M.; RODÀ, I. (2015): Tarraco, la primera capital, Catalan Historical Review 8,117-133.

MACIAS, J. M.; MENCHÓN, J.; MUÑOZ, A.; TEIXELL, I. (2007): De seu del Concili Provincial a Seu Metropolitana. Treballs arqueològics a la Catedral de Tarragona (20002003), Arqueología Medieval 3, 8-29.

MAR, R. (1993): El recinto de culto imperial en Tarrraco y la arquitectura flavia, El monuments provincials de Tarraco $(\mathrm{R}$. Mar, ed.), Tarragona.

MAR, R.; RUIZ DE ARBULO, J.; VIVÓ, D. (2013): Los genios de los conventus iuridici y el lugar de reuniones del concilium provinciae Hispaniae citerioris. ¿Una "curia" de uso provincial en Tarraco?, Las sedes de los "Ordines decurionum” en Hispania: análisis arquitectónico y modelo tipológico (B. Soler, P. Mateos, J. M. Noguera, J. Ruiz de Arbulo, eds.), Anejos de AEspA 67, 25-41.

MAR, R.; RUIZ DE ARBULO, J.; VIVÓ, D.; BELTRÁN-CABALLERO, J. A. (2015), Tarraco. Arquitectura y urbanismo de una capital provincial romana, vol. II: La ciudad Imperial, Tarragona.

MASIER, A. (2006): Il questore di Adriano L. Roscius [---]cius Celer M[---] Postumus Mam[---] Vergilius Staberia[---], Epigraphica 68, 1-2, 103-115.

NOGALES, T.; ÁLVAREZ, J. M., (2006): Fora Augustae Emeritae. La interpretatio provincial de los patrones metropolitanos, El concepto de lo provincial en el mundo antiguo. Homenaje a la Profesora Pilar León (D. Vaquerizo; J. F. Murillo, eds.), 419-449.

ORTIZ DE URBINA, E. (1999): La respublica en las comunidades hispanas a partir de la fórmula epigráfica omnibus honoribus functus, Ciudades privilegiadas en el Occidente romano (J. González, ed.), Sevilla, 127-146.

ORTIZ DE URBINA, E. (2006): La exaltación de la élite provincial, Epigraphica 68, 45-84.

OZCÁRIZ, P. (2013): La administración de la provincia Hispania citerior durante el Alto Imperio Romano, Barcelona.

PANZRAM, S. (2002): Stadtbild und Elite: Tarraco, Corduba und Augusta Emerita zwischen Republik uns Späntantike, Stuttgart.
PANZRAM, S. (2003): Los flamines provinciae de la Bética: autorepresentación y culto imperial, AEspA 76, n. ${ }^{\circ}$ 187-188, 121-130.

PAVÓN, P. (2010): De abigeis puniendis (D. 47, 14, 1; Coll. 11, 7, 13): el rescripto de Adriano sobre el robo de ganado en la Bética, Gerión 28.1, 275-307.

PIETRINI, S. (1990): A proposito della sanzione nel reato di abigeato, Studi Senesi 102, 455-473.

$P I R^{2} \mathrm{C}=$ GROAG, E. (1036): Prosopographia Imperii Romani saec. I, II, III. Editio altera (PIR $\left.{ }^{2}\right)$, Pars II, Berlin.

$P I R^{2} \mathrm{R}=$ WACHTEL, K. (1999): Prosopographia Imperii Romani saec. I, II, III. Editio altera (PIR $\left.{ }^{2}\right)$, Pars VII.1, Berlin.

PME = DEVIJVER, H. (1976-1993): Prosopographia militarum equestrium quae fuerunt ab Augusto ad Gallienum, vols. I-VI, Leuven.

RIT = ALFÖLDY, G. (1975): Die römischen Inschriften von Tarraco. Berlin.

RODRÍGUEZ NEILA, J. F. (1978): Los Jueces de las Cinco Decurias oriundos de la Hispania romana, HA 8, 17-66.

ROVIRA, J. (1993): Alguns aspectes per a la contextualizació histórica del fòrum provincial de Tàrraco, El monuments provincials de Tàrraco. Noves aportacions al seu coneixement (R. Mar, ed.), Tarragona, 195-228.

RUIZ DE ARBUlO, J. (1990): El foro de Tarraco, Cypsela 8, 119-138.

RUIZ DE ARBULO, J. (1993): Edificios públicos, poder imperial y evolución de las elites urbanas en Tarraco, Ciudad y comunidad cívica en Hispania en los siglos II y III d. C. (Madrid 1990), Madrid, 93-113.

RUIZ DE ARBULO, J. (1998): Tarraco : escenografia del poder, administración y justicia en una capital provincial romana (s. II a.c.-II d.c.), Empúries 51, 31-61.

RUIZ DE ARBULO, J. (2007): Bauliche Inszenierung und literarische Stilisierung: das Provinzialforum von Tarraco, Städte im Wandel (S. Panzram, ed.) (Hamburg 2005), Münster, 149-212 (= Nuevas cuestiones en torno al foro provincial de Tarraco, Butlletí Arqueològic, ep. V, 29, Tarragona, 2008, 4-66).

RUIZ DE ARBULO, J. (2014): El signaculum de Caius Valerius Avitus, duoviro de Tarraco y propietario de la villa de Els Munts (Altafulla), Pyrenae 45.1, 125-151.

SANTALUCIA, B. (2009): Adriano e il rango sociale dei rei, Studi in onore di Remo Martini, vol III, Siena, 473-482.

SETTIPANI, CH. (2002): Continuité gentilice et continuité familiale dans les familles senatoriales romaines a l'époque imperiale, Mythe et réalité. Addenda I-III (juillet 2000- octobre 2002), Prosopographica et Genealogica, 2-127.

SILLIÈRES, P.; MAGALLÓN, M. A.; NAVARRO, M. (1995): El municipium Labitolosanum y sus notables novedades arqueológicas y epigráficas, AEspA 68, 107-130.

SPAUL, J. (2000): Cohors 2 : the evidence for and a short history of the auxiliary infantry units of the Imperial Roman Army, Oxford. 
SPEIDEL, M. P. (1977): The Roman Army in Arabia, Aufstieg und Niedergang der römischen Welt (ANRW) II.8, Berlin-New York, 687-730.

STYLOW, A. U. (2006): La epigrafía y el culto imperial en Augusta Emerita: nuevos epígrafes del conjunto provincial de culto imperial, El foro provincial de Augusta Emérita: un conjunto monumental de culto imperial (P. Mateos, ed.), Anejos de AEspA 42, 297-314.

SYME, R. (1988): Journeys of Hadrian, ZPE 73,159-170.
TED'A (1989): El foro provincial de Tarraco, un complejo arquitectónico de época flavia, AEspA 62, n. ${ }^{\circ}$ 159-160, 141-191.

TRILLMICH, W. (1993): Foro provincial und foro municipal in den hauptstadten der drei hispanischen Provinzen: eine Fiktion, Ciudad y comunidad cívica en Hispania en los siglos II y III d. C. (Madrid 1990), Madrid, 115-125.

WILLIAMS, W. (1987): Individuality in the Imperial Constitutions: Hadrian and the Antonines, JRS 66, 67-83.

WILLIAMSON, C. H. (1987): A Roman Law from Narbonne, Athenaeum 65, 173-89. 